\title{
La Katábasis de Max y de Bernat Metge
}

\author{
Pau GonzÁlez Gost
}

Pau González Gost estudió Humanidades en la Universitat Pompeu i Fabra especializándose en literatura y filosofía, cursó el Máster de Formación de Profesorado y en la actualidad está terminando un doctorado en Literatura y lenguas modernas. Ha publicado relatos de ficción en antologías de escritores jóvenes, artículos en periódicos locales y dos entrevistas: una a Max (Quimera) y otra a Pere Joan (La Bolsa de Pipas); también creó y llevó adelante varios blogs. En la actualidad trabaja como profesor de secundaria de Literatura castellana y Filosofía.

Fecha de recepción: 2 de mayo de 2016

Fecha de aceptación definitiva: 15 de mayo de 2016 


\title{
Resumen
}

En este artículo se analizará la revisión - y la consecuente transformación- de un mito clásico —el mito de Orfeo- por parte de dos autores muy distintos: el dibujante barcelonés Max y el funcionario de la casa real Bernat Metge. El primero se acerca al mito en su obra Katábasis (introspección psico-mitológica) y el segundo en un fragmento de Lo somni (mimetismo respecto al esquema clásico). El artículo trata de explicar la presencia de Orfeo en Lo somni a través de una historia escrita seis siglos más tarde.

Palabras clave: Max, Bernat Metge, Orfeo, mito, psicología, intertextualidad

\begin{abstract}
In this article we are going to analyse the revision and transformation of a classical myth -Orpheus myth - of Max and Bernat Metge. The first author's approach is done in his opus Katábasis (psico-mythologic introspection) and the second author's approach in his opus Lo somni (classic structure's mimesis). The article explains the Orpheu presence in Lo somni through a history written six centuries after.
\end{abstract}

Keywords: Max, Bernat Metge, Orpheus, myth, psychology, intertextuality

\section{Cita bibliográfica}

González Gost, P. «La Katábasis de Max y de Bernat Metge», en CuCo, Cuadernos de cómic, n. ${ }^{\circ} 6$ (2016), pp. 80-91. 
En este artículo se analizará la revisión - y la consecuente transformación - de un mito clásico —el mito de Orfeo- por parte de dos autores muy distintos: el dibujante barcelonés Max y el funcionario de la casa real Bernat Metge. Los dos autores tratan un mito clásico sin ser humanistas - al menos no lo son en el sentido canónico del término- y realizan un acercamiento desde dos puntos de vista muy diferentes. El primero se acerca al mito en su obra Katábasis (introspección psico-mitológica) y el segundo en un fragmento de Lo somni (mimetismo respecto al esquema clásico). El artículo trata de explicar la presencia de Orfeo en Lo somni a través de una historia escrita seis siglos más tarde. Para ello han hablado los propios textos, y a través de ellos se ha definido el discurso que viene a continuación.

El mito de Orfeo y Eurídice aparece explicado in extenso por primera vez en la literatura latina. Exactamente en unos versos de Virgilio, en el libro iv de las Geórgicas. Esta es la versión canónica del mito y la que ha ejercido más influencia. Bernat Metge se inspira en esta versión y en la que aparece en Las metamorfosis de Ovidio. De esta manera, la versión del mito clásico que presenta Bernat Metge es una mezcla de estos dos textos.

En el fragmento de Lo somni que explica el mito de Orfeo encontramos una única voz narrativa que pertenece al cantor. Metge a través de la voz del cantor cuenta su desgraciada historia de amor. Eurídice, huyendo del «amor libidinoso» de Aristeo sufre la mordedura de una serpiente y muere. Orfeo baja a los infiernos para buscar a su amada y le ruega a Cerbero, portero del infierno, que le abra las puertas. Una vez dentro sus palabras y su música conmueven de tal manera a las criaturas infernales, a Plutón y a su esposa Proserpina que le otorgan el don de sacar a Eurídice del reino de los abismos. Aunque le imponen una condición: no se puede girar hasta que no llegue al mundo exterior. Cuando está a punto de terminar su ascenso al mundo de los vivos, caminando «por las vueltas de un camino largo, tenebroso, cuando estaba en la parte más alta del margen del río» Orfeo «temiendo que ella lo abandonara y ansioso por verla» se gira y Eurídice cae. Entonces el cantor extiende los brazos, pero estos no tocan más que el viento que se levanta por la caída de la amada y Eurídice reingresa de manera definitiva en el Hades. En el cómic de Max este instante que cierra la historia-, se resuelve con un primer plano del ojo de Orfeo y la frase: «La vi esfumarse y sólo quedó una lágrima suspendida en el aire». En las dos revisiones del mito aparece el concepto de viento o aire como metáfora de la ausencia de la amada.

Un Orfeo desconsolado vuelve a los infiernos pidiendo una segunda oportunidad, pero Cerbero no se la concede. Orfeo, triste, sube al monte Ródope a cantar y alabar las virtudes de la «vida sin compañía femenina». También se dice que «en el monte no había sombras» y que con su canto llegaron «árboles de distinta naturaleza» y muchos animales. Pero las 


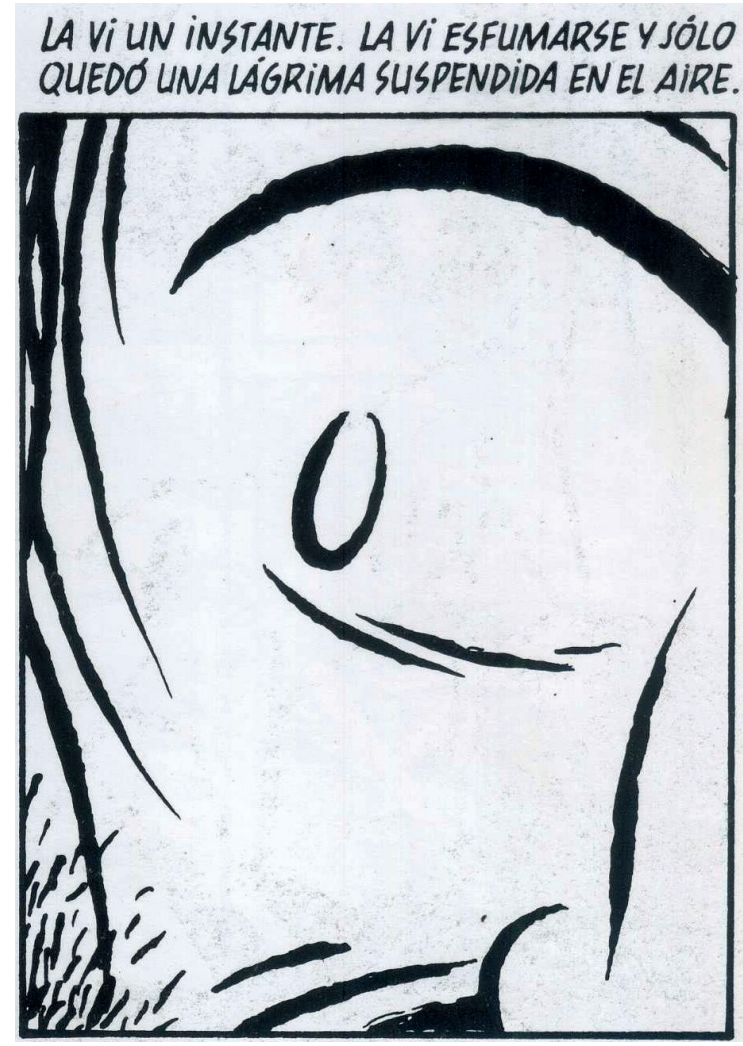

FIG. 1. Max. Como perros! Barcelona, La Cúpula, 2007, p. 42.

mujeres se enfadan debido a su canto y lo matan. Finalmente Orfeo baja a los infiernos, esta vez para quedarse. «Donde reencontré a Eurídice, mi esposa, con la que sigo, seguro de que ahora en adelante no la perderé». De esta manera tan optimista finaliza el texto de Bernat Metge.

Lo que predomina en el texto es el canto de Orfeo para recuperar a Eurídice, la lista de dioses que se conmueven ante su canto, la retirada de Orfeo al monte y su muerte. Las dos muertes de Eurídice se tratan de manera más breve.

Max nos sitúa a través del cómic en otro ámbito discursivo. Utiliza un soporte diferente, donde cuentan factores como la serialidad, los colores y la puesta en página. Además su revisión del mito nos explica una historia distinta a la de Metge.

Cuando Orfeo ingresa en el infierno y se pone a cantar Hades se enfada y le dice: «Tu canto ha traído el tiempo a este lugar sin tiempo, y ahora mi fatiga se hace intolerable. Debería ejercitar toda mi crueldad en ti por esto!». La condición humana y mortal de Orfeo introduce el tiempo en el reino eterno e infernal del príncipe Hades. Aunque este dice: «has logrado conmover el helado corazón de mi esposa, a quién no me está permitido negar nada».Hades avisa a Orfeo de que no se gire para mirar a Eurídice hasta que no abandone 


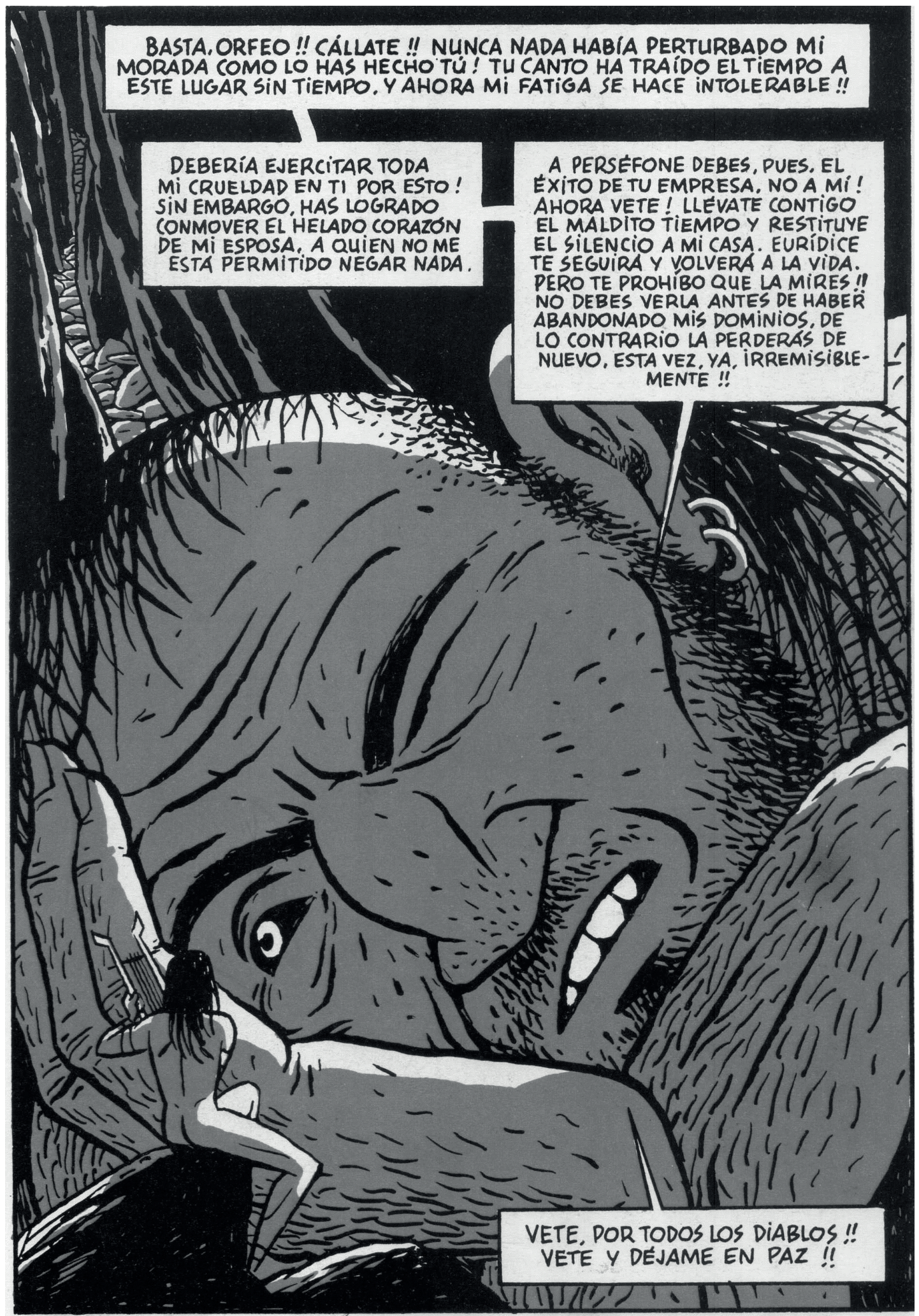

FIG. 2. Max. Op. cit. p. 33. 

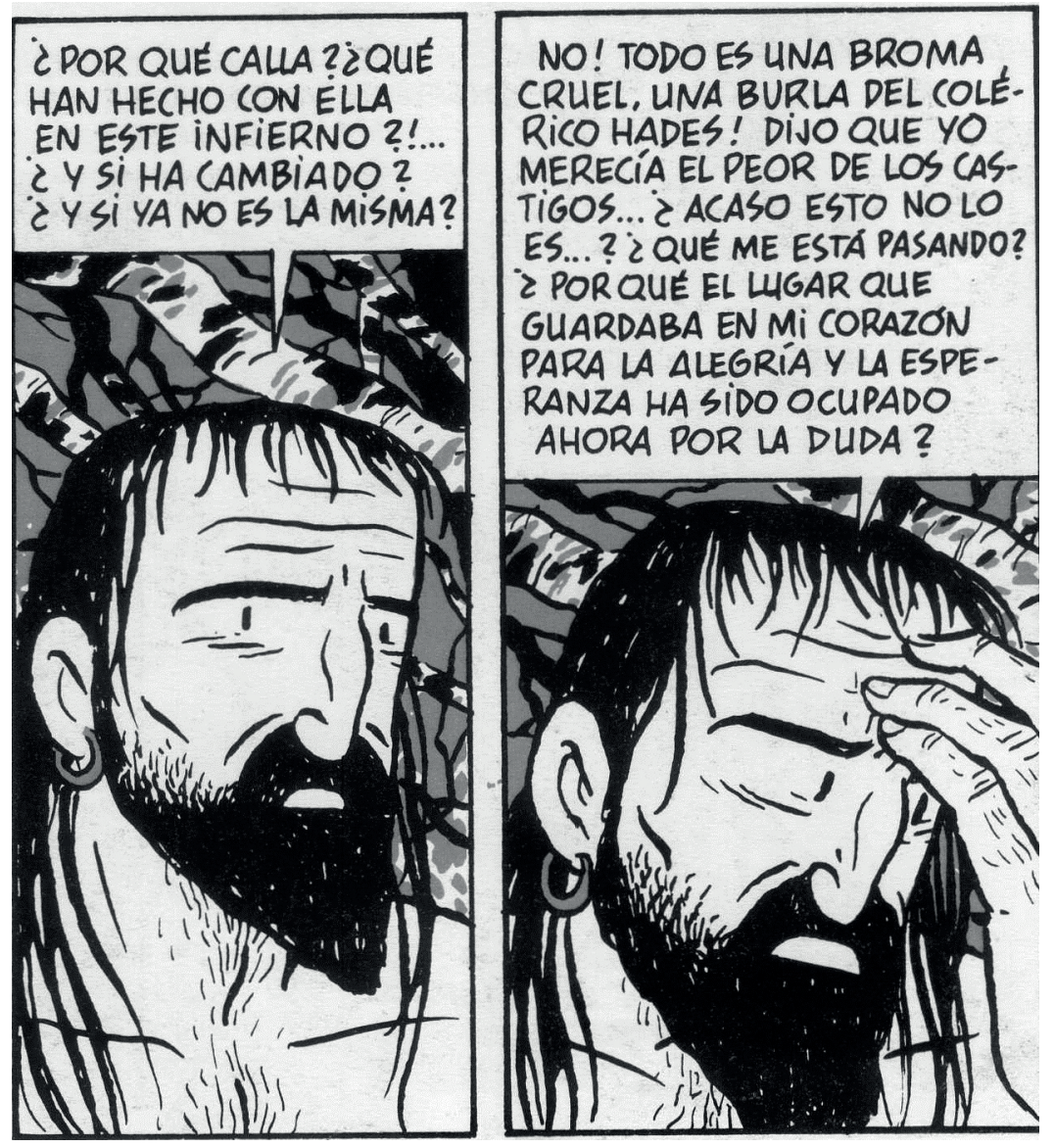

FIG. 3. Max. Op. cit. p. 37.

sus dominios. El canto de Orfeo en Lo somni también produce una alteración temporal. $\mathrm{El}$ infierno deja de funcionar y la eternidad se interrumpe. Orfeo dice que los dioses que escucharon su canto «cesaron en el ejercicio de sus oficios», y que «todas las almas que aquí había, olvidando las penas que sufrían, hicieron lo mismo». Por lo tanto, a causa del canto de Orfeo el castigo eterno de los condenados se para y como en el cómic de Max, el tiempo se deja sentir en el infierno por boca de Orfeo.

Al Orfeo de Katábasis lo guían unos perros blancos y ciegos hacia el camino de salida. A medida que avanzamos por las viñetas, entramos en el remolino de dudas e inseguridades del cantor, que se debate entre la esperanza de salir del mundo de las sombras y la desesperación que le causa el silencio de Eurídice (en el texto de Ovidio Orfeo y Eurídice avanzan «a través de mudos parajes silenciosos». $)^{1}$ Finalmente, no puede resistir la tentación y se gira para comprobar si su amada lo sigue. Se gira mientras profiere gritos miserables y es advertido por un perro blanco: «No, Orfeo, nooooo!!». ${ }^{2}$ En la última viñeta vemos el zoom

\footnotetext{
${ }^{1}$ Ovidio. Metamorfosis. Madrid, Espasa Calpe, 1994, p. 339.

2 Max. Como perros! Barcelona, La Cúpula, 2007. p. 42.
} 
al ojo de Orfeo y el texto que explica como desaparece su esposa. La historia se cierra con la misteriosa frase: «... el traidor era yo». ${ }^{3} \mathrm{El}$ final de Max es más trágico que el de Metge ya que ni tan solo en el último momento podemos ver a la bella Eurídice. Esta ocultación de la figura de la amada a lo largo de toda la historia intensifica la sensación de ausencia y nos ayuda a empatizar con el protagonista.

La acción se desarrolla íntegramente dentro del infierno. Las dos primeras láminas son las únicas que escapan a este patrón. La primera, muestra al poeta penetrando en el reino de las sombras, y la segunda a Orfeo cantando a Hades. Max deconstruye el mito clásico y reduce su contenido al momento en que Orfeo es seguido por Eurídice dentro del infierno. Los elementos predominantes en el cómic son la inseguridad de Orfeo, el paisaje repetitivo configurando un bosque que nunca termina y los diálogos entre los perros y el cantor.

Bernat Metge, a diferencia de Max (que construye un Orfeo instrospectivo y psicológico y en consecuencia subjetivo), describe el mito con más distancia. Metge deja que el lector juzgue según sus convicciones, no realiza ningún juicio de valor explícito sobre las acciones del cantor. En cambio la visión de Max sí que juzga y culpabiliza a Orfeo — «el traidor era yo»—.
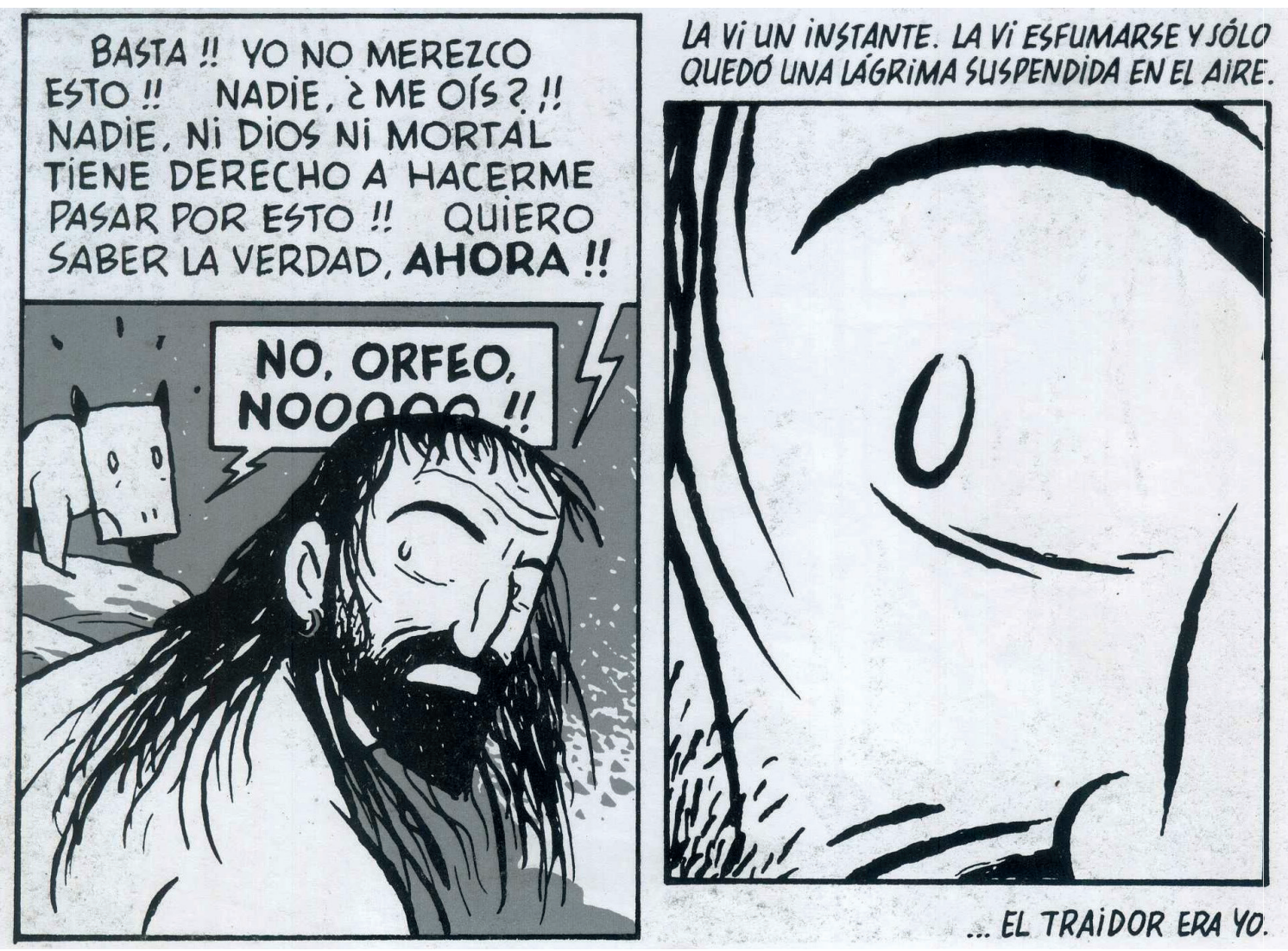

FIG. 4. MAX. Op. cit. p. 42.

${ }^{3}$ Ibid. 
Pau González Gost

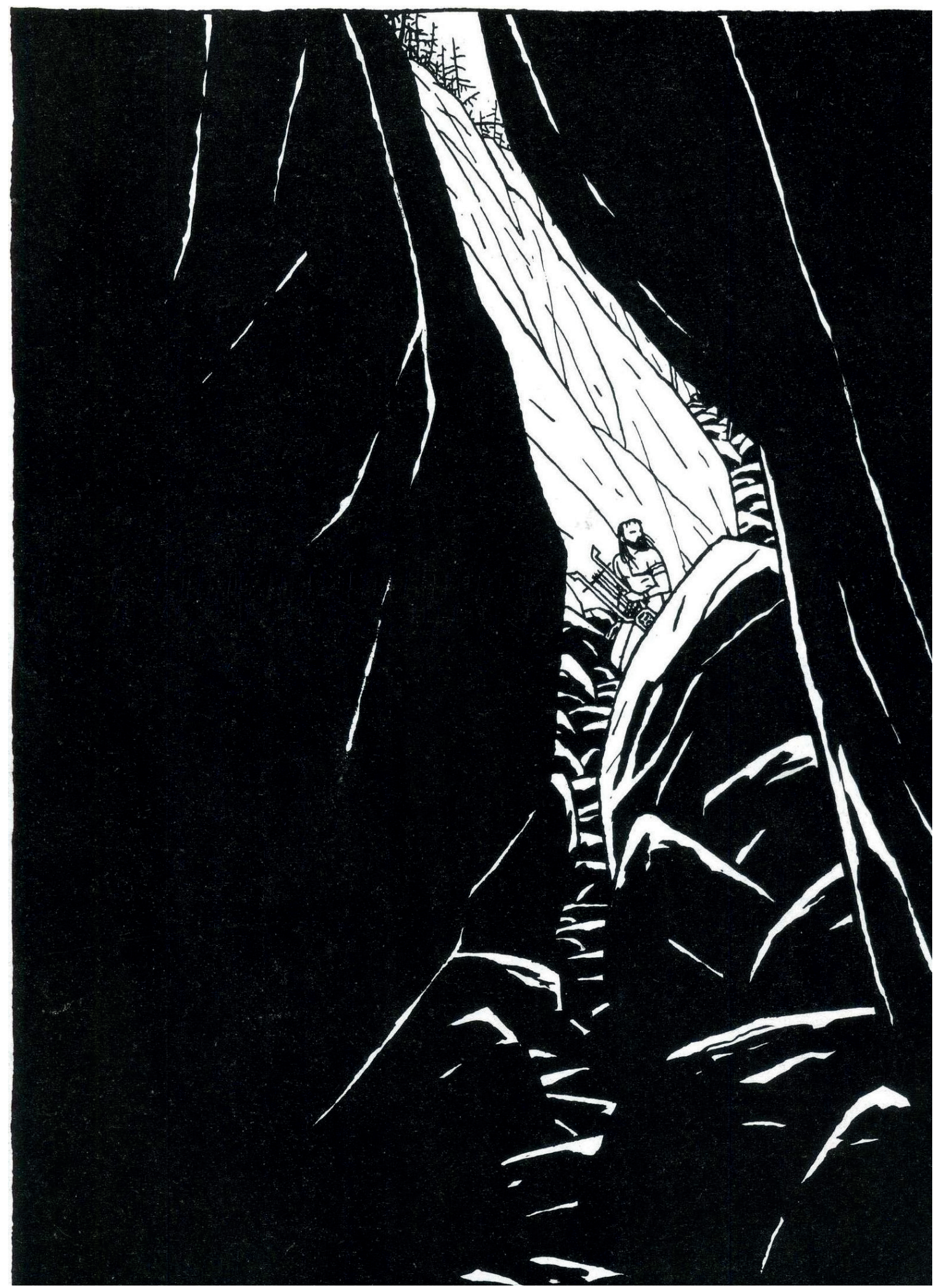

FIG. 5. Max. Op. cit. p. 32. 


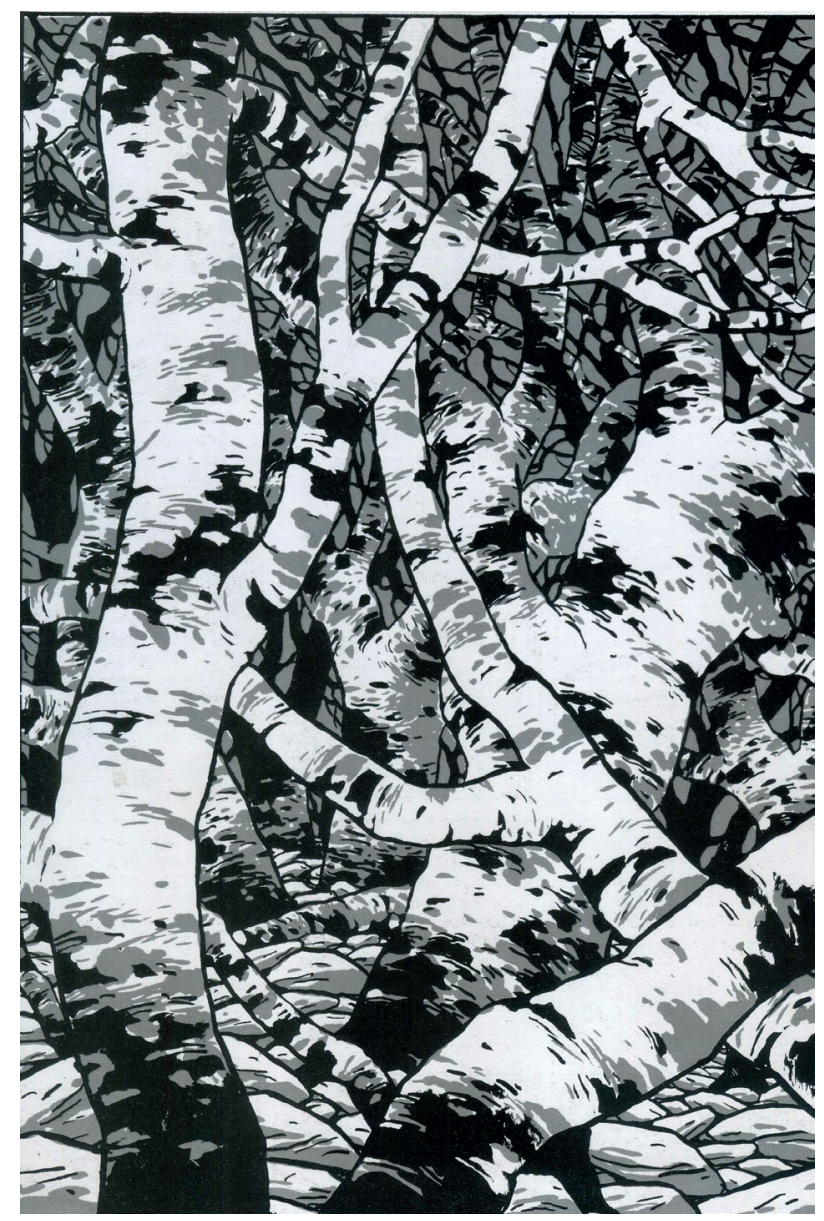

FIG. 6. Max. Op. cit. p. 40.

Pero con la reconstrucción de las causas psicológicas que obligaron al cantor a girarse hacia Eurídice, a través de los diálogos y las reflexiones, justifica el héroe y humaniza el arquetipo clásico. Cualquiera de nosotros, en nuestro día a día, podemos sufrir las dudas de Orfeo en su bajada a los infiernos. Con lo cual nos convertimos en protagonistas de muchas katábasis a lo largo de nuestras vidas. Por este motivo las preocupaciones y las dudas que se le presentan al héroe son algunas de las preocupaciones que recorren el subconsciente contemporáneo. Y ¿cuál es el espacio que mejor expresa estas preocupaciones? Este espacio, desde Freud hasta nuestros días, es el subconsciente. El infierno, además de un símbolo de inmersión en el mundo de las sombras es un símbolo de introspección psicológica. Por eso Max reduce el mito: para presentar las contradicciones internas del protagonista en el espacio de su propia psique. Así pues esta culpa es redentora. Max nos está diciendo que Orfeo se giró porque se sentía inseguro y no hay nada más humano que la inseguridad. Es decir que si de alguna cosa es culpable Orfeo es de ser humano. El héroe maxiano se convierte en una representación de toda la humanidad.

De esta manera llegamos a un callejón sin salida: el hecho de ser culpable de su desgracia es lo que realmente lo hace humano y el hecho de ser humano lo catapulta a la misma des- 
gracia. Así pues el mito órfico se transforma en el más humano de los mitos y nos transmite una tierna simpatía.

Hete aquí el porqué de que Metge presente a Orfeo haciendo uso de la captatio benevolentia al principio de su parlamento: «Poco después, Orfeo, con gracia, gesto alegre y buena cara, empezó a decir esto que sigue». ${ }^{4}$ Por lo tanto, a través de Max podemos hacer una interpretación de esta simpatía: la profunda y desesperada humanidad del cantor. Además también en las Geórgicas de Virgilio encontramos una disculpa poética por parte del autor al error de girarse de Orfeo: «locura ciertamente perdonable, si los Manes supieran perdonar!». ${ }^{5}$

Llegados a este punto podemos releer (o reinterpretar) el Orfeo de Bernat Metge desde una nueva perspectiva. Si aceptamos la visión de Max, este mito habla de la inseguridad y la duda inherentes a la raza humana. Así pues, la elección de este personaje encajaría dentro de la filosofía utilitaria que recorre la obra de Lo somni. Este personaje, simpático y benevolente, simboliza la eterna imperfección de la humanidad lo que implica que todos nos podemos equivocar porque somos humanos. Y como ha afirmado Martí de Riquer, ${ }^{6}$ el libro de Metge no deja de ser (entre muchas otras cosas) una manera de justificarse y defenderse. Y qué mejor manera para justificarse que apelar a aquello que todos (en mayor o en menor grado) compartimos: nuestra condición humana. Después de la Katábasis de Max, Orfeo actúa como uno de los motivos redentores que podemos encontrar en la obra Lo somni.

Para concluir, lo que me ha parecido más interesante es el hecho de que la misma historia de la literatura produzca explicaciones inconscientes de sí misma, y que estas explicaciones sirvan para transformar contenidos que a priori parecen solidificados (el texto canónico del mito de Orfeo, la obra de Lo somni). De esta manera, podemos considerar la existencia de un texto infinito tal como lo hizo Borges, un texto hecho de relaciones intertextuales eternas que transmutan constantemente los propios significados.

\footnotetext{
${ }^{4}$ Metge, B. Lo somni. Barcelona, Quaderns Crema, 2003. p. 109.

5 Virgilio. Geórgicas. Madrid, Cátedra, 1994, p. 279.

${ }^{6}$ Riquer, M. Història de la literatura catalana, vol. 3. Barcelona, Ariel, 1993, p. 409.
} 
DEBO CONFIAR ENTI, EURIDICE, V SOBRE TODO EN MI MISMO, PERO TENGO TANTO MIEDO AL FRACASO.. A SER ENGAÑADO, A QUE TODO ESTE SUFRIMIENTO HAYA SIDO VANO...! NO SE QUÉ PENSAR, YA NO ENTIENDO NADA...

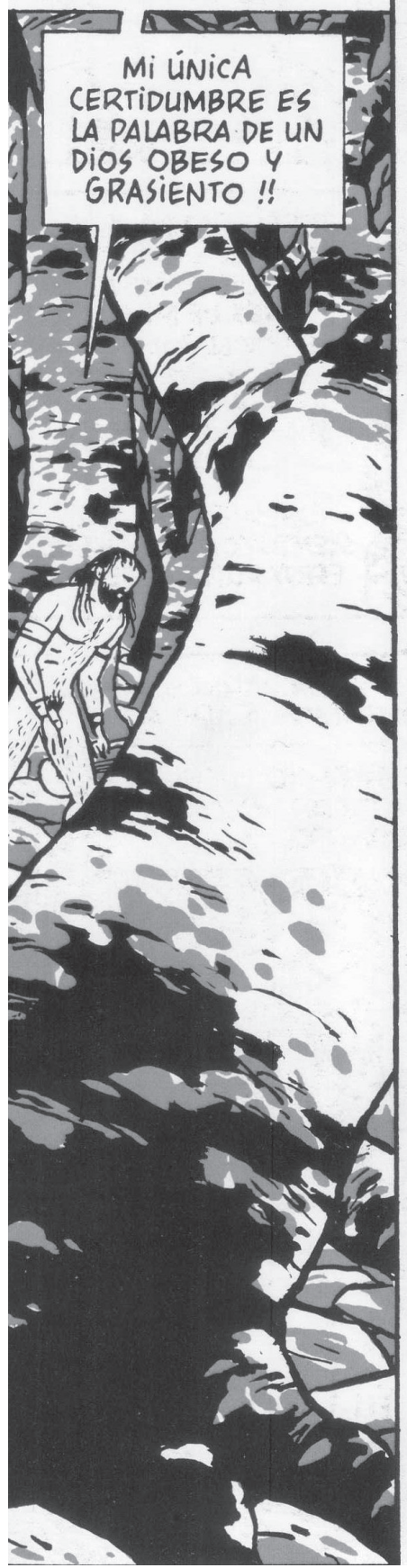

¿ Y SI ES ELLA QUIEN, DESPUES DE TODO, NO QUIERE REGRESAR CONMIGO? ¿Y SI SU AMOR POR MI HA...? NO! NO ES POSIBLE !! ELLA NO PUEDE IGNORAR TODO LO QUE ESTOY HACIENDO! NO PUEDE PENSAR QUE LA HE ABANDONADO!!

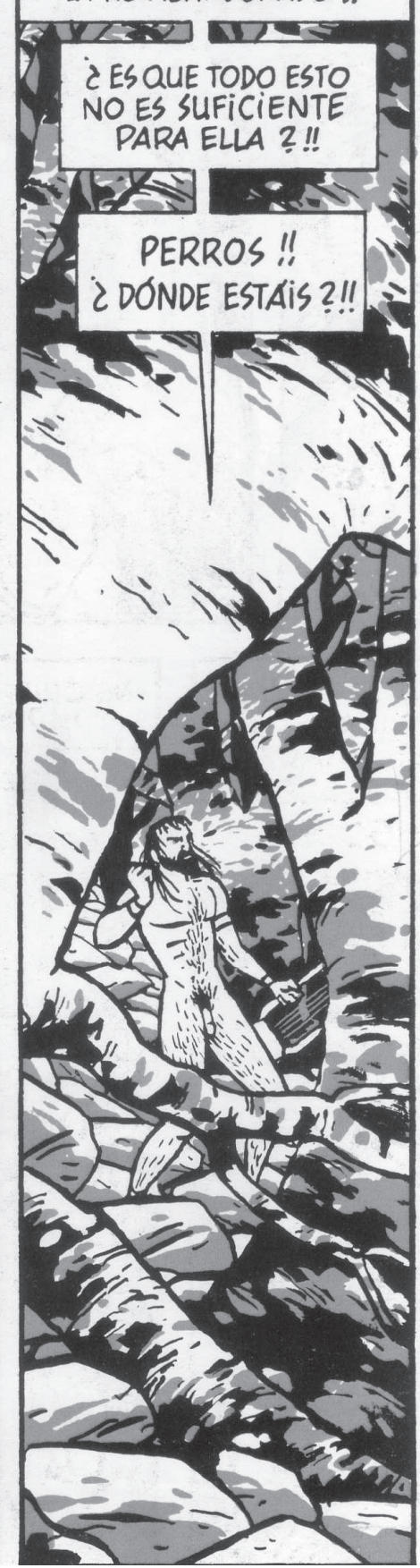

¿ POR QUÉ OS ESCONDEIS? HABLADME, PERROS,O ME VOLVERE LOCO!!
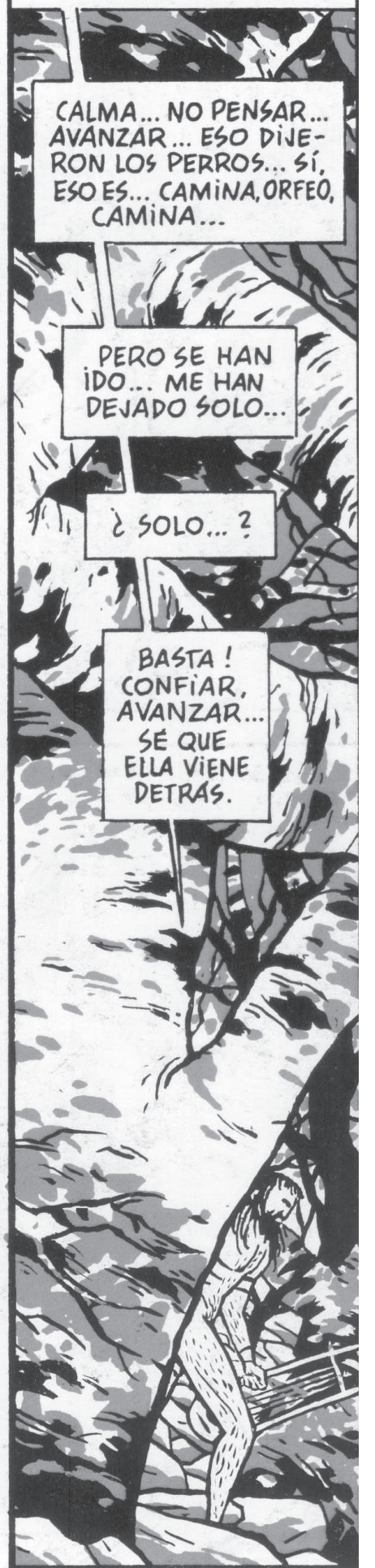

FIG. 7. Max. Op. cit.p. 39. 


\section{Bibliografía}

Alighieri, D. Infern (Divina Comèdia). Barcelona, Proa, 2000.

Max, Como perros! Barcelona, La Cúpula, 2007.

Metge, B. Lo somni. Barcelona, Quaderns Crema, 2003.

—El sueño. Barcelona, DVD, 2006.

Ovidio. Les metamorfosis VII-XV. Barcelona, la Magrana, 1997.

—Metamorfosis. Madrid, Espasa Calpe, 1994.

Riquer, M. Història de la literatura catalana, vol. 3. Barcelona, Ariel, 1964.

Virgilio. Geòrgiques. Barcelona, Fundació Bernat Metge, 1963.

—Geórgicas. Madrid, Cátedra, 1994. 